\title{
Mulheres Trans, Moda para Todas
}

Women Trans, Fashion for All

LARANJEIRA, Anita Poffo ; Acadêmica; Univille - Universidade da Região de Joinville.

anita.poffo@gmail.com

MOREIRA, Bruna Tiani; Acadêmica; Univille - Universidade da Região de Joinville.

brunatianimoreira08@gmail.com

PETRY, Camila; Acadêmica; Univille - Universidade da Região de Joinville.

camilaptry@gmail.com

DICKIE, Isadora Burmeister; Doutoranda, Univille - Universidade da Região de Joinville.

isadora.dickie@gmail.com

RIBEIRO, Mariê Souza; Mestra, Univille - Universidade da Região de Joinville.

marie.ribeiro91@gmail.com

\section{Resumo}

Considerada como uma das responsáveis pela criação de padrões estéticos que impactam a vida das pessoas de diversas formas, positivas ou negativas, a indústria da moda está, aos poucos, fazendo-se mais democrática no sentido de conseguir quebrar os padrões impostos por ela mesma. Perante o desafio de trabalhar com as singularidades e particularidades das pessoas, o presente projeto teve como objetivo realizar estudos dentro dos aspectos ergonômicos e de design para o desenvolvimento de uma coleção de moda praia para o público-alvo denominado mulheres transgênero. Desta forma, visou-se o conforto, a estética e a segurança das mesmas.

Palavras Chave: mulheres transgênero; ergonomia; moda praia.

\begin{abstract}
Considered to be one of those responsible for creating aesthetic standards that impact people's lives in a variety of ways, both positive or negative, the fashion industry is gradually becoming more democratic in order to be able to break the standards imposed by herself. Faced with the challenge of working with the singularities and particularities of people, the present project aims to carry out studies within the ergonomic and design aspects for the development of a collection of beachwear for the target audience called transgender women. In this way, it aims at comfort, aesthetics and safety.
\end{abstract}

Keywords: transgender women; ergonomics; beachwear. 


\section{Introdução}

A moda praia para mulheres transgênero ainda é um grande tabu. A invisibilidade da população transexual precisa ser discutida e, para isso, faz-se necessário repensar projetos e inovar para uma moda mais inclusiva que atenda as possíveis necessidades deste público. Dentre esses espectros de gêneros existem pessoas (1) cisgênero (cis), ou seja, "pessoas que se identificam com o gênero que lhes foi determinado quando de seu nascimento" (Gomes, 2012 p. 10); (2) pessoas transgênero (trans), "que abrange o grupo diversificado de pessoas que não se identificam, em graus diferentes, com comportamentos e/ou papéis esperados do gênero que lhes foi determinado quando de seu nascimento" (Gomes, 2012 p. 25); e (3) pessoas com identidade não-binária, isto é, aquelas que não se preocupam em se dividir em gêneros (Reis e Pinho, 2016).

Apesar da moda praia ser o setor que mais destaca no Brasil, investindo em originalidade, tanto nas cores quanto na modelagem, não há um produto pensado para o nicho de mercado que as mulheres trans ocupam. Sendo o biquíni brasileiro tido como referência na moda mundial, entende-se a relevância em inovar também neste setor, onde o país pode vir a se destacar como uma moda praia inclusiva focada para um público ainda mais abrangente.

O presente artigo apresenta os resultados de um projeto desenvolvido no curso de Design de Moda da Universidade de Região de Joinville - UNIVILLE, abrangendo duas disciplinas: Projeto de Moda I e Ergonomia. Assim, apresenta-se parte da revisão bibliográfica relacionada à temática, elaborada a partir de uma pesquisa desk (pesquisa exploratória através de informações já publicadas e disponíveis) sobre: conceitos de mulheres trans, ergonomia, moda praia e design de moda. Por fim, apresenta e discute sobre o tema, apresentando-o como uma solução viável para o mercado, com uma moda mais inclusiva e para todas.

\section{Referencial Teórico}

A moda praia é um segmento de significância dentro da indústria da moda no Brasil, que, por sua vez, é considerado um dos maiores produtores e consumidores de moda praia do mundo. Este segmento, portanto, tem sido componente fundamental na construção da moda nacional.

Considerando as observações feitas nesta pesquisa, foi percebido que um problema evidente é a de uma calcinha (ou a parte inferior do biquíni) que consiga disfarçar o volume da genitália masculina para mulheres trans que optaram em não realizar a cirurgia ou estão no período da transição.

\subsection{Mulheres Trans: Em Busca de uma Definição.}

Uma pessoa trans é aquela que tem a identidade de gênero diferente da designada em seu nascimento (sexo biológico). É necessário destacar que ser uma pessoa transexual ou travesti é uma questão de auto identificação, ou seja, a pessoa assume e designa a si mesma o conceito que melhor se identifica.

$\mathrm{Na}$ maioria dos casos, pessoas trans passam por um processo de transição, onde normalmente fazem uso de hormônios para se sentirem mais confortáveis com o seu próprio corpo. De acordo com Bento (2012, p. 19) "no processo transexualizador, inclusive nas cirurgias de transgenitalização, é necessário submeter-se a um rigoroso protocolo que inclui terapia psicológica obrigatória e a realização de testes psicológicos". O total de pacientes atendidos no 
Brasil não é divulgado pelo Ministério da Saúde. Para a comunidade médica mundial, os casos de pessoas transgênero ainda estão na lista de doenças mentais. A concepção de gênero muitas vezes é mais relacionada com a função da genitália do que, simplesmente, com as diferenças anatômicas conforme o site do EBC (Empresa Brasil de Comunicação) nem todas as pessoas transgêneros precisam ou querem fazer a cirurgia de readequação sexual.

De acordo com a pesquisa do IBGE (Instituto Brasileiro de Geografia e Estatística) de 2013, a expectativa de vida desse grupo social não passa dos 35 anos, menos da metade da média nacional de 74,9 anos da população em geral. Atualmente, o Brasil é o país onde há mais assassinatos de pessoas trans no mundo. Este dado foi obtido pela organização não governamental Transgender Europe (rede europeia de organizações que apoia os direitos da população transgênero) que reuniu dados de janeiro de 2008 a dezembro de 2014. Esse levantamento revelou que $51 \%$ dos assassinatos de indivíduos trans na América Central e do Sul aconteceram no Brasil. Segundo Rodriguez (2014, p.27) "ocorre uma constante patologização da sexualidade, uma vez que o desejo de uma identidade de gênero não normativa é tratada como doença, determinando as práticas de saúde, e as formas como a sociedade percebe a comunidade Trans."

Existem diversas barreiras a serem enfrentadas e a invisibilidade da população transsexual precisa ser discutida. Sendo assim, faz-se necessário uma moda que atenda as possíveis necessidades deste público. Entende-se que "a diversidade sexual e de gênero fazem parte das expressões da dimensão sexual humana e, portanto, devem ser respeitadas e consideradas em suas diferenças" (RODRIGUEZ, 2014, p. 27). Dentre as diferenças a serem consideradas a ergonomia da vestimenta atua como um agente de inclusão para o desenvolvimento de produtos, e quebrar essa barreira e invisibilização do público trans também é entender como a moda pode ajudar nos aspectos sociais e culturais em busca da igualdade.

\subsection{Ergonomia}

Muitas necessidades humanas são satisfeitas mediante o uso de produtos desenvolvidos para suprir uma incapacidade ou limitação. Na modelagem do vestuário, a ergonomia e a antropometria são ferramentas importantes pois podem contribuir para minimizar os impactos negativos e solucionar problemas.

Segundo lida (2005), a ergonomia prevê que os produtos sejam adaptados aos usuários, e não o contrário. A ergonomia abrange aspectos físicos, cognitivos e organizacionais. Para o presente artigo, foi priorizada a ergonomia física, que aborda o estudo físico do corpo humano para que seja realizado o correto dimensionamento do produto. Isso engloba medições antropométricas, testes biomecânicos, prototipagem, pesquisa quantitativa e qualitativa com usuários para coleta de dados. São a ergonomia e a usabilidade que, quando presentes nos produtos, possibilitam que o usuário satisfaça seus objetivos e expectativas, como proposto (Watkinson, 2013).

Neste sentido, apresentam-se os conceitos fundamentais e princípios metodológicos da ergonomia na criação e desenvolvimento de um produto de moda praia para mulheres trans. Após pesquisas teóricas partiu-se para a etapa de entrevista com as mulheres trans, conforme serão apresentados no item 2.2 com o objetivo de identificar dificuldades e compreender necessidade para o consumo de moda praia. 


\subsection{Moda Praia Inclusiva}

Conforme dados da ABIT (Associação Brasileira da Indústria Têxtil), o setor de moda praia movimenta cerca de US\$ 1,5 bilhão por ano, apenas no mercado interno. Parte disso pode ser atribuído às extensas dimensões litorâneas do país e o clima tropical na maior parte do território nacional, normalmente moderado a quente, em quase todas as estações e contribuem para manter o fluxo constante no consumo de itens de moda praia. O campo do design procura transformar as necessidades humanas em produtos ou serviços que visam a melhoria de sua qualidade de vida. "O designer, portanto, assume o papel de facilitador, ou agente ativador, de inovações colaborativas, promovendo interações na sociedade" (KRUCKEN, 2009, p. 48).

Nesta perspectiva, o papel do design extrapola a criação de produtos, passando a interferir sobre o comportamento dos usuários e sobre a forma "como os seres humanos relacionam-se através da influência mediadora dos produtos" (Buchanan, 2001, p. 11). O design, portanto, constitui-se como um importante condutor de transformação e inovação sendo uma ponte entre a pesquisa básica e a inovação, realizando e transformando as descobertas em produto pronto para ser consumido.

Partindo da ideia de Ciacco (2003, p. 11), de que inovar representa "um bem social", o design pode ser apresentado como uma forma de unir cidadãos, beneficiar a comunidades e fazer crescer o país. Sendo assim, surgem novas abordagens da moda sobre sua influência e sua utilização como ferramenta de inclusão social, denominada moda inclusiva, que tem como essência a democratização, a valorização e a inclusão das pessoas de forma a humanizar a moda.

\section{Referencial Prático}

Para a confirmação e validação dos pontos levantados até agora, mediante a aprovação do Comitê de Ética em Pesquisa com Seres Humanos (parecer número 2.351.880), utilizou-se como referencial prático a observação do usuário em entrevista através de registro fotográfico e videográfico, obtidos apenas como fonte de pesquisa para análise de informações, sem que seja feita a divulgação dos mesmos. Após levantamento dos problemas existentes nas peças acessíveis ao público, realizada uma análise de similares (figura 1), construído um mapa mental para visualização do sistema UTO (usuário, tarefa e objeto) (figura 2) e hierarquização dos problemas ergonômicos com a ferramenta tabela matriz GUT (gravidade, urgência e tendência) (tabela 1). Por fim, foi utilizado o método de validação com o público para seleção da peça e aplicadas sugestões de melhorias necessárias.

\subsection{Análise de Similares}

Uma análise sincrônica, feita em Setembro de 2017, revelou que peças de moda praia especializadas em mulheres trans são muito escassas. Foi encontrada apenas uma marca brasileira que trabalha com este conceito, sendo ela, Tereza Cabana Moda Trans.

Figura 01 - Pesquisa de similares. 


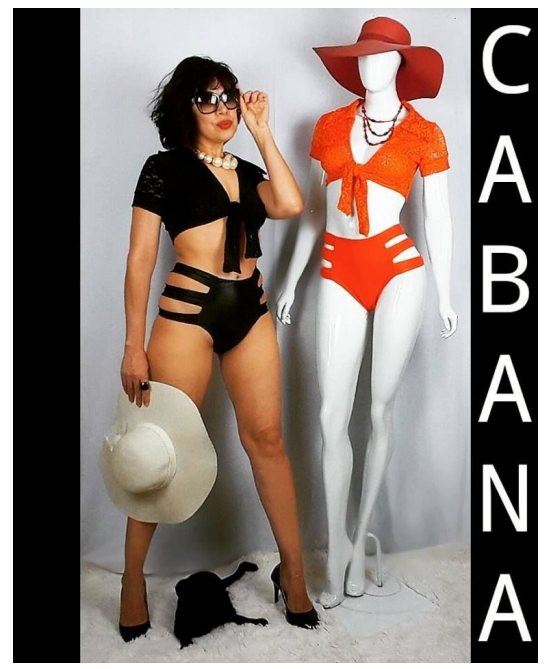

Fonte: terezacabana.wordpress.com (2018).

A marca tem uma produção independente e artesanal, divulgada prioritariamente boca a boca, não tem uma loja física e show room e trabalha com pedidos por demanda. Suas peças têm pouca informação de moda, não há uma coleção estruturada, mas atendende uma das maiores necessidades das clientes, com peças bem estruturadas e que se adaptam bem ao corpo.

\subsection{Entrevista com o Público}

Foram realizadas entrevistas com três mulheres trans, tendo como objetivo ajudar a identificar as características e dificuldades encontradas para o consumo de moda praia, a fim de um melhor desenvolvimento do projeto de pesquisa. Sintetizando as entrevistas, viu-se que, em geral, as mulheres entrevistadas consomem moda praia ao menos 1 ou 2 vezes ao ano e gastam em média $\mathrm{R} \$ 120,00$. Em sua maioria consomem peças criadas para mulheres cis e adaptam para seu uso.

Existe uma grande dificuldade em encontrar peças do vestuário de moda praia que correspondam às suas necessidades biológicas e que agradam esteticamente. Na maioria das vezes usam outra calcinha por baixo do biquíni para que ofereça maior sustentação e segurança. Quando é necessário comprar um conjunto único, tendem a optar por tamanho maior do que costumam usar. Porém, há problemas com a modelagem das peças, pois em cima fica sobrando e embaixo fica no tamanho certo ou vice e versa.

Das preferências apresentadas, destacam-se: peças com forro duplo (estampado de um lado e liso do outro), que a calcinha seja maior no entrepernas, que tenham opção de bojo removível, sejam ajustáveis, adaptáveis, com materiais resistententes e bem estruturados. As mulheres entrevistadas sentem-se confortáveis quando seguras do que estão vestindo, por conta do conforto psicológico, no caso de se sentirem bonitas; ou conforto físico, que sintam-se bem independente de movimentação, local ou peça que estão vestindo, sem machucar ou apertar nenhuma parte do seu corpo.

As entrevistadas acreditam que não exista visibilidade do seu biotipo no mercado e que os fabricantes deveriam estudar melhor suas anatomias e necessidades. Para uma moda praia mais inclusiva no mercado, uma das mulheres apresenta como uma solução a produção de peças que 
tanto mulheres trans quanto mulheres cis pudessem consumir levando em conta todos os aspectos de conforto e segurança para ambas.

\subsection{Sistema Usuário, Tarefa e Objeto - UTO e Gravidade, Urgência e Tendência - GUT}

A partir dos dados levantados nas análises de similares e entrevistas foram determinadas as categorias do sistema UTO (Usuário, Tarefa e Objeto). Sendo assim, ficam definidas dentro das categorias: o Usuário como as mulheres trans; a Tarefa, frequentar a praia e locais relacionados a esse tipo de vestuário, pois necessita sentir o conforto físico e psicológico, e por último o objeto, um biquíni que seja adaptável, resistente, durável e confortável.

Figura 02 -Sistema Usuário-Tarefa-Objeto.

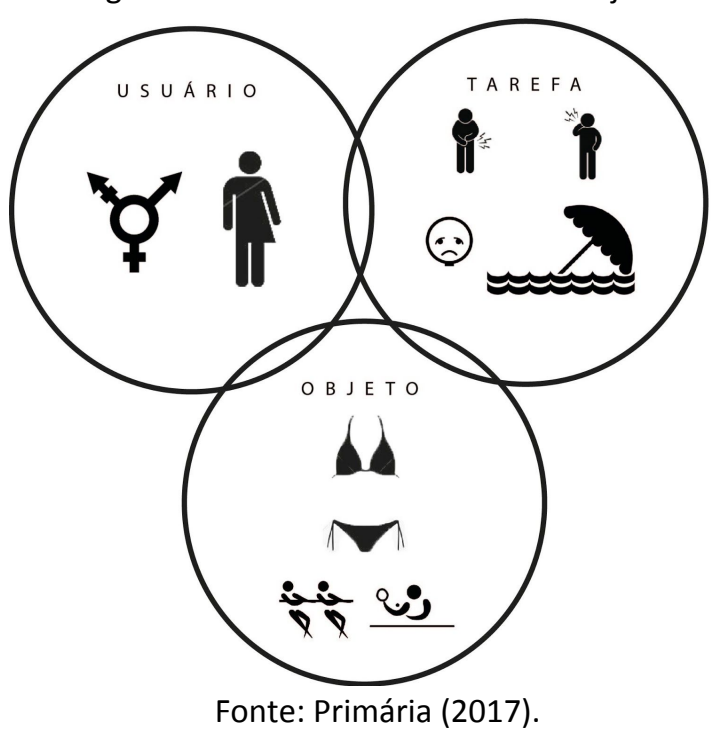

Para a priorização de resolução dos problemas, utilizou-se a ferramenta matriz GUT (Gravidade, Urgência e Tendência). Apontando como nota 5 o seu maior agravante e com nota 1 o menor.

Tabela 1 - Tabela Matriz GUT

\begin{tabular}{|c|c|c|c|c|}
\hline Problemas Ergonômicos & G & U & T & Total \\
\hline $\begin{array}{l}\text { Pouco espaço na parte } \\
\text { frontal do entrepernas }\end{array}$ & 5 & 5 & 1 & 11 \\
\hline Falta de firmeza do tecido & 4 & 4 & 3 & 11 \\
\hline
\end{tabular}




\begin{tabular}{|c|c|c|c|c|}
\hline $\begin{array}{c}\text { Pouca durabilidade da } \\
\text { peça }\end{array}$ & 3 & 3 & 2 & 8 \\
\hline $\begin{array}{c}\text { Cores e estampas sem } \\
\text { informações de tendência } \\
\text { de moda }\end{array}$ & 3 & 2 & 3 & 8 \\
\hline $\begin{array}{c}\text { Tiras laterais } \\
\text { desconfortáveis e não } \\
\text { ajustáveis }\end{array}$ & 4 & 5 & 1 & 10 \\
\hline
\end{tabular}

Fonte: Primária (2017).

Conforme tabela 1 , pode-se dizer que os maiores agravantes estão relacionados a modelagem, pois com 11 pontos na hierarquização dos problemas ergonômicos relacionados ao sistema da tabela GUT encontram-se pouco espaço na parte frontal do entrepernas da calcinha e falta de firmeza do tecido. Outro aspecto de grande relevância encontrado foi o desconforto em em relação as tiras laterais da calcinha do biquíni com 10 pontos do total. Seguindo a ordem decrescente, com 8 pontos, encontramos problemas relacionados a durabilidade da peça e a escassez de produtos com informação de moda agregada.

\subsection{Pesquisa de Tendências}

Para complementar as informações obtidas sobre a estética da peça a ser desenvolvida, realizou-se uma pesquisa de tendências. Para a moda praia do verão 2018, ressaltam as estampas tropicais, como por exemplo a utilização de folhagens e estampas florais, que ganham espaço dentro das modelagens de maiôs e biquínis. Pode-se mencionar também as amarrações em strappy onde são posicionadas estrategicamente para deixar a mostra partes do corpo e criar um efeito visual bastante agradável. Geometria, babados volumosos, silhuetas de ombro a ombro, ou de um ombro só, decotes cavados, e amarrações são pontos desse verão a serem levados em consideração.

Figura 03 - Painel de tendências. 

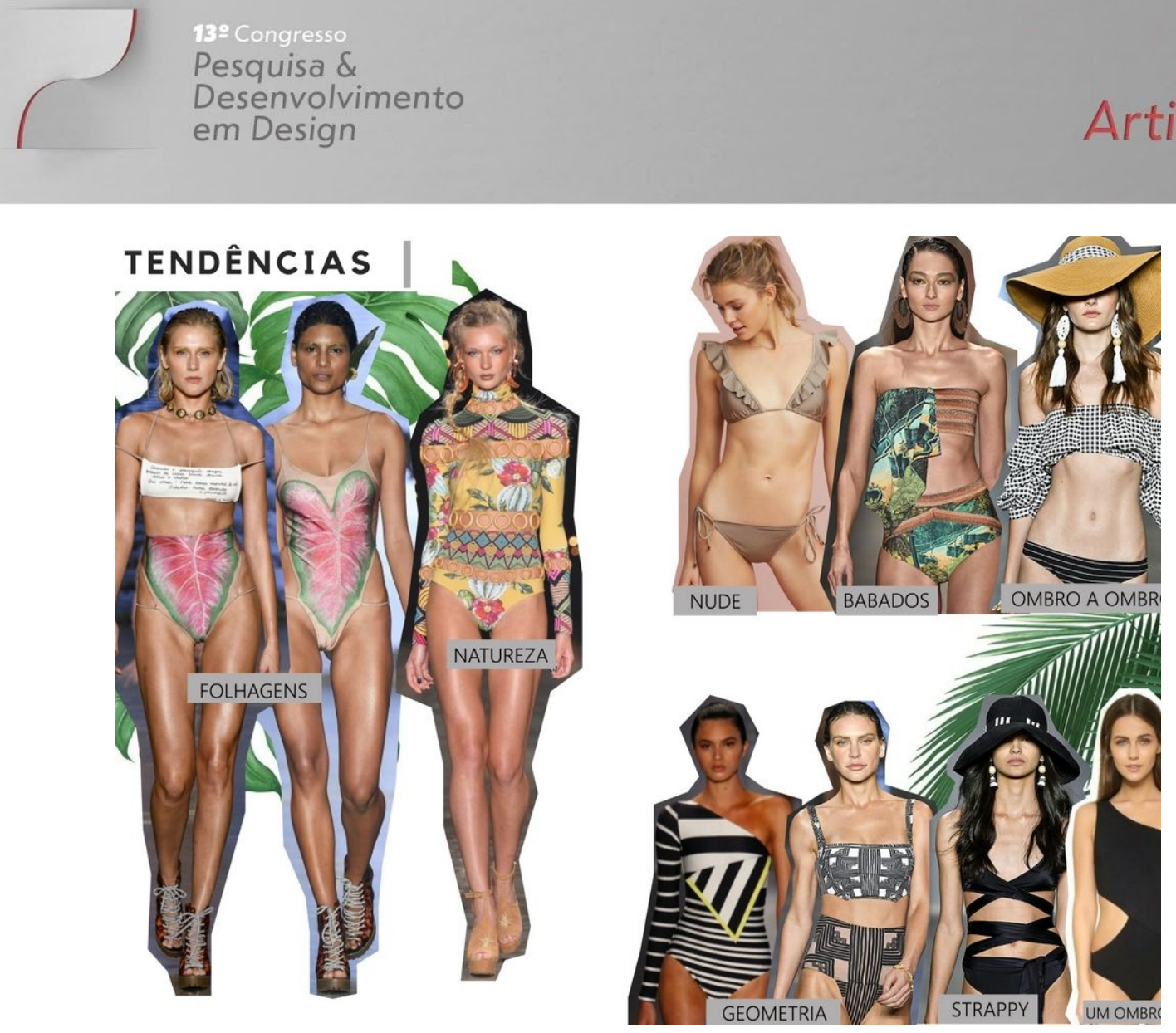

Fonte: Primária(2017).

\section{Público Alvo}

O público-alvo foi desenvolvido com base nas informações coletadas durante a etapa de entrevista do projeto. São mulheres trans, que estão na faixa etária dos 20 aos 35 anos, gostam de estar em contato com a natureza, possuem uma personalidade forte, autoconfiança, acreditam que a liberdade só existe quando é compartilhada e respeitada por todos. Criativas na hora de se vestir, usam a moda como forma de expressão. Querem sentir-se jovens, belas e participantes do meio social; por isso, preservam cuidados com o corpo, valorizam a estética e vêem na praia um ambiente plural para coexistir com a grande diversidade de pessoas que a frequentam.

Figura 04 - Painel de público alvo. 


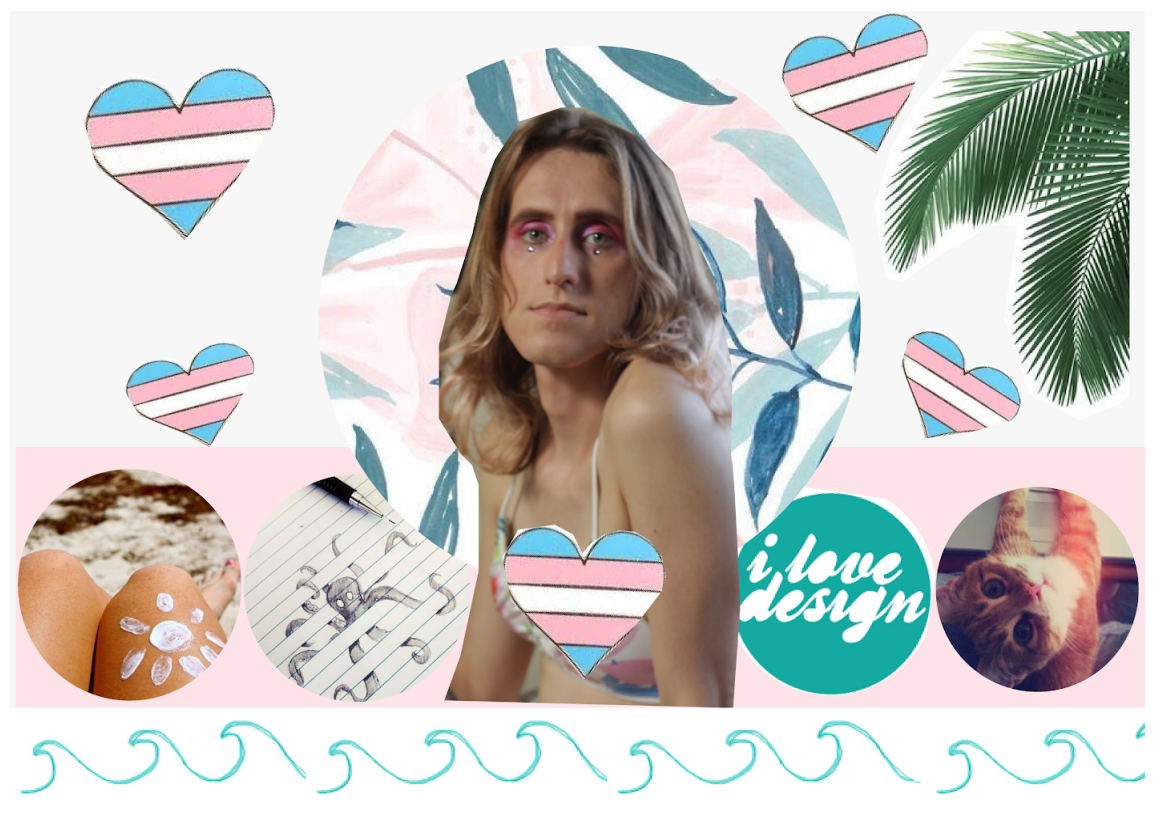

Fonte: Primária(2017).

\section{Definição da Peça}

Unindo as informações obtidas nas pesquisas de tendências com os gostos e preferências do público, pode-se trabalhar em cima de um conceito/tema para desenvolver alternativas que poderão atender as necessidades dos problemas encontrados até então, e por fim, a seleção da peça final mediante a validação com o público.

\subsection{Conceito e Tema}

O Sagrado Feminino é uma filosofia que fomenta princípios sobre aspectos físicos e psicológicos da figura feminina. Este estilo de vida é o acordar da consciência da mulher, a apropriação do corpo em sua total liberdade de padrões estabelecidos pela sociedade.

$\mathrm{Na}$ atualidade, esta conexão que havia sido perdida está sendo resgatada. Através do Sagrado Feminino em que a mulher contemporânea sente o apelo interno em conectar-se consigo mesma e com a natureza. Com isso, promove-se um autoconhecimento, a liberdade e o empoderamento em relação a si e de onde habita.

A mulher brasileira em toda a sua diversidade, está representada na figura 05, aflora uma fauna rica e tropical, de belezas distintas e ainda inexploradas, pois em cada mulher contemporânea floresce uma mulher sagrada que deve ser cultivada e preservada.

Figura 05 - Painel de Tema/conceito. 


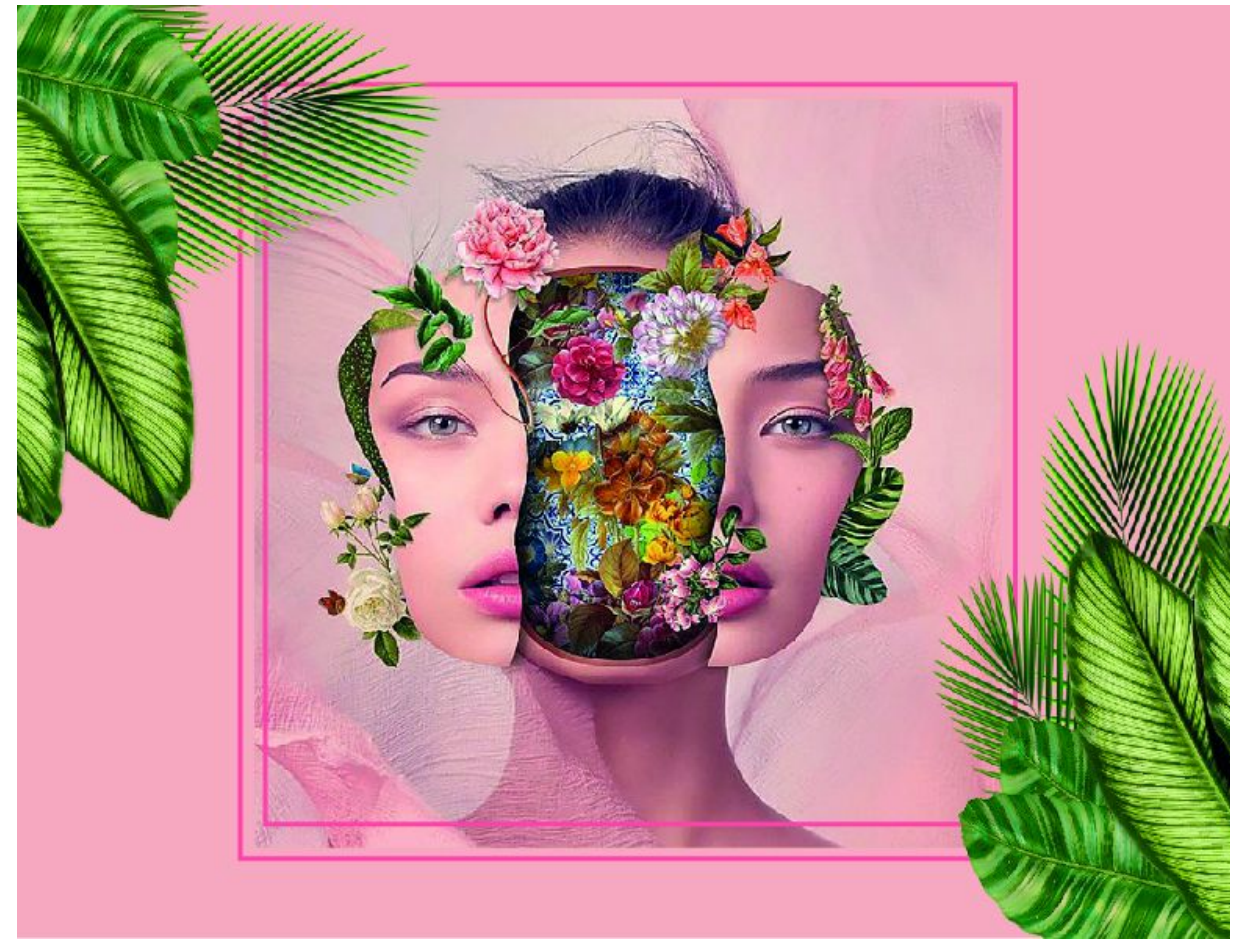

Fonte: Primária (2017).

\subsection{Cartelas de Cores e Materiais}

As cores selecionadas para a criação do look remetem a natureza nos tons de verde e amarelo. Já os tons de rosa, branco e azul são associadas a bandeira transgênero.

Figura 06 - Cartela de Cores.
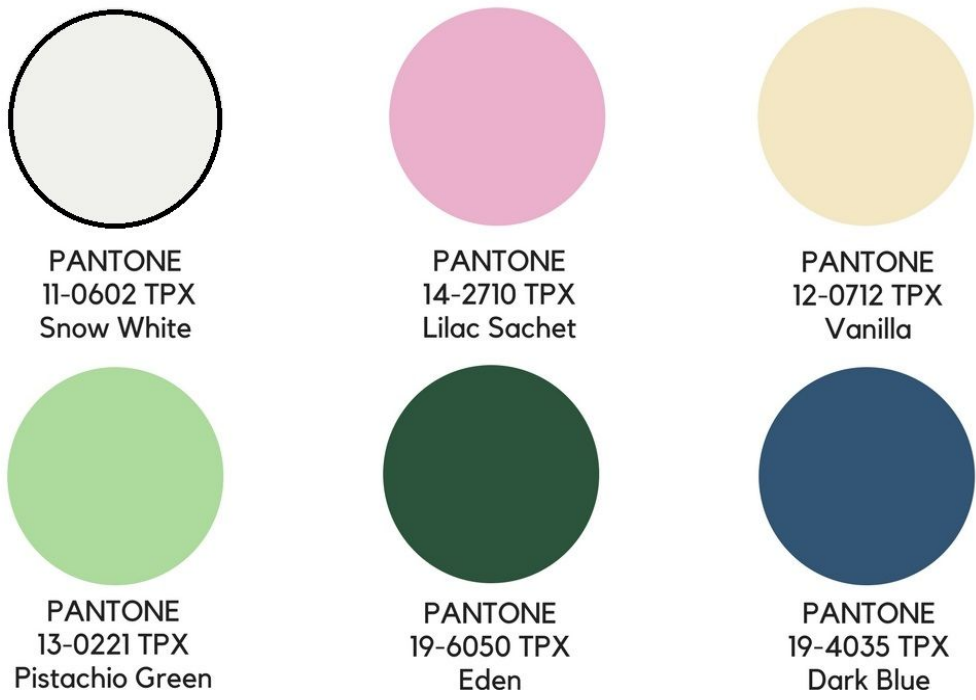

Fonte: Primária.

Em relação aos materiais, primeiro foi eleito o tecido fitness, que é mais estruturado, possui boa elasticidade, se adequa bem ao corpo possibilitando a mobilidade, segurança e 
conforto para a peça principal. A poliamida foi utilizada para fazer detalhes e acabamentos e por fim o dry fit utilizado na confecção de uma saída de praia para composição do look.

Figura 07 - Cartela de materiais.

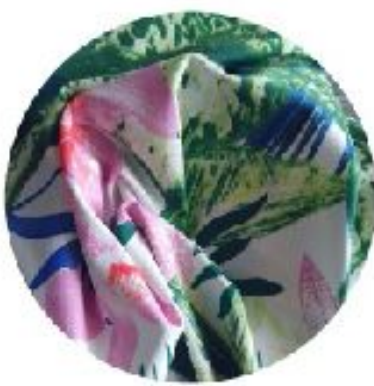

Tecido Fitness

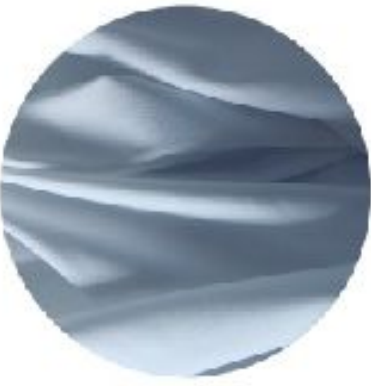

Tecido Poliamida

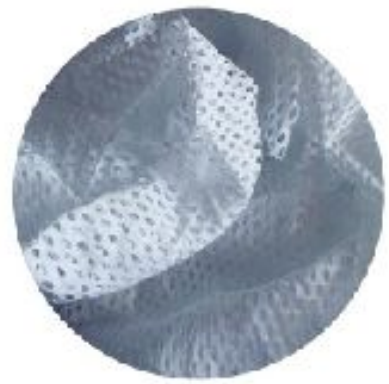

Tecido Dry Fit

Fonte: Primária (2017).

\subsection{Geração de Alternativas}

Das 15 alternativas geradas, foram trabalhadas modelagens que pudessem: ser ajustável com amarrações e recortes para diferentes biotipos; oferecer boa sustentação com materiais bem estruturados e resistentes, sem que exista a necessidade de usar outra peça por baixo do biquini; ser mais larga no entrepernas da calcinha, para maior conforto; ter forro duplo, para maior variedade de uso (dois lados, um estampado e outro liso); retirar o bojo conforme a necessidade; e por fim, agregar informação de moda e design, aliando tendências a peças diferentes (criativas).

Figura 08 - Geração de alternativas.

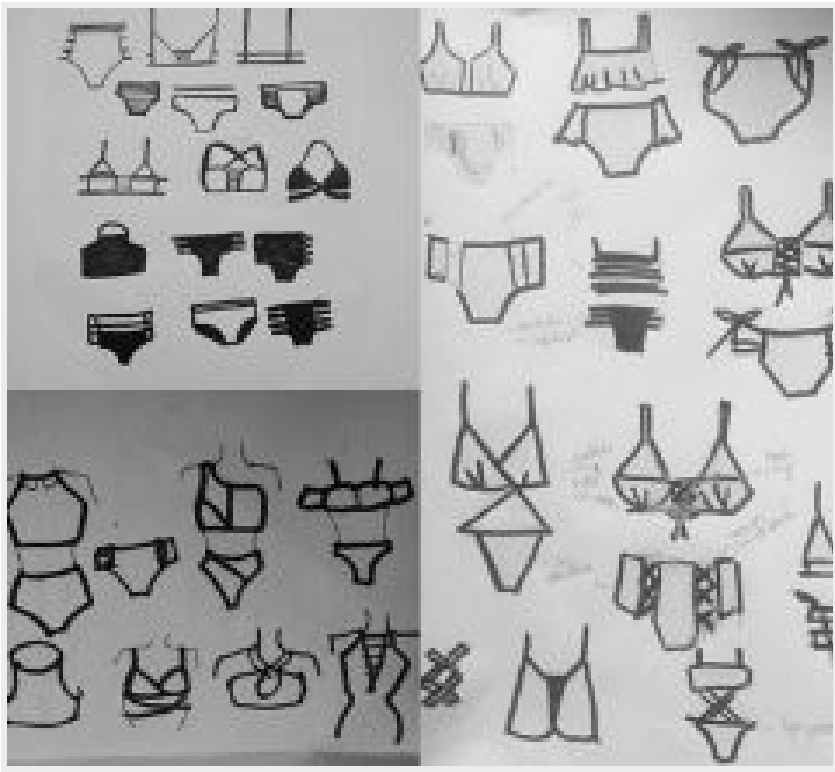

Fonte: Primária (2017) 


\subsection{Validação com o Público}

Após a geração de alternativas foi realizada uma seleção das peças e a validação das mesmas com as entrevistadas. Sendo escolhida a que melhor atendesse os critérios ergonômicos e estéticos apontados pelo público. Abaixo a tabela com os requisitos de sugestões aplicadas e a validação do público.

Tabela 2 - Validação com público alvo.

\begin{tabular}{|c|c|c|c|}
\hline Número & Sugestões & Justificativa & $\begin{array}{c}\text { Validação do } \\
\text { público }\end{array}$ \\
\hline 1 & Modelagem diferenciada. & $\begin{array}{c}\text { Na parte da genitália é necessário que a } \\
\text { modelagem seja maior do as dos modelos de } \\
\text { mulheres cis, pelo fato de que o produto irá } \\
\text { atender a necessidade de esconder o órgão } \\
\text { masculino. }\end{array}$ & Sim \\
\hline 2 & Tecido encorpado e resistente. & $\begin{array}{c}\text { Para que não seja mais necessário o uso de } \\
\text { outra peça íntima por baixo (relato feito pela } \\
\text { usuária) será utilizado um tecido com mais } \\
\text { firmeza e segurança.. }\end{array}$ & Sim \\
\hline 3 & Amarração ajustável & $\begin{array}{c}\text { Justamente pelo fato de o produto atender a } \\
\text { necessidade do público de esconder o } \\
\text { membro íntimo, a peça será ajustável, } \\
\text { aumentando ou diminuindo sua flexibilidade } \\
\text { conforme for sendo vestida. }\end{array}$ & Sim \\
\hline
\end{tabular}

Fonte: Primária (2017).

\subsection{Peça Selecionada}

A peça selecionada é composta por um sutiã e calcinha do biquíni, sendo que a parte superior possui bojo removível, amarração frontal entre os seios, costas e pescoço, visando versatilidade e ajuste adequado a usuária. Já na parte inferior foi ajustado o entrepernas, sendo aumentado aproximadamente 3 centímetros, em relação a uma calcinha de biquíni para mulher cis. Foi inserido também opções de amarração lateral para proporcionar um efeito visual agradável, gerar equilíbrio entre as peças e melhor modelagem ao corpo. A estampa de tema floral vai de acordo com a pesquisa de tendência e referido gosto das entrevistadas.

Figura 09 e 10 - Foto da peça. 

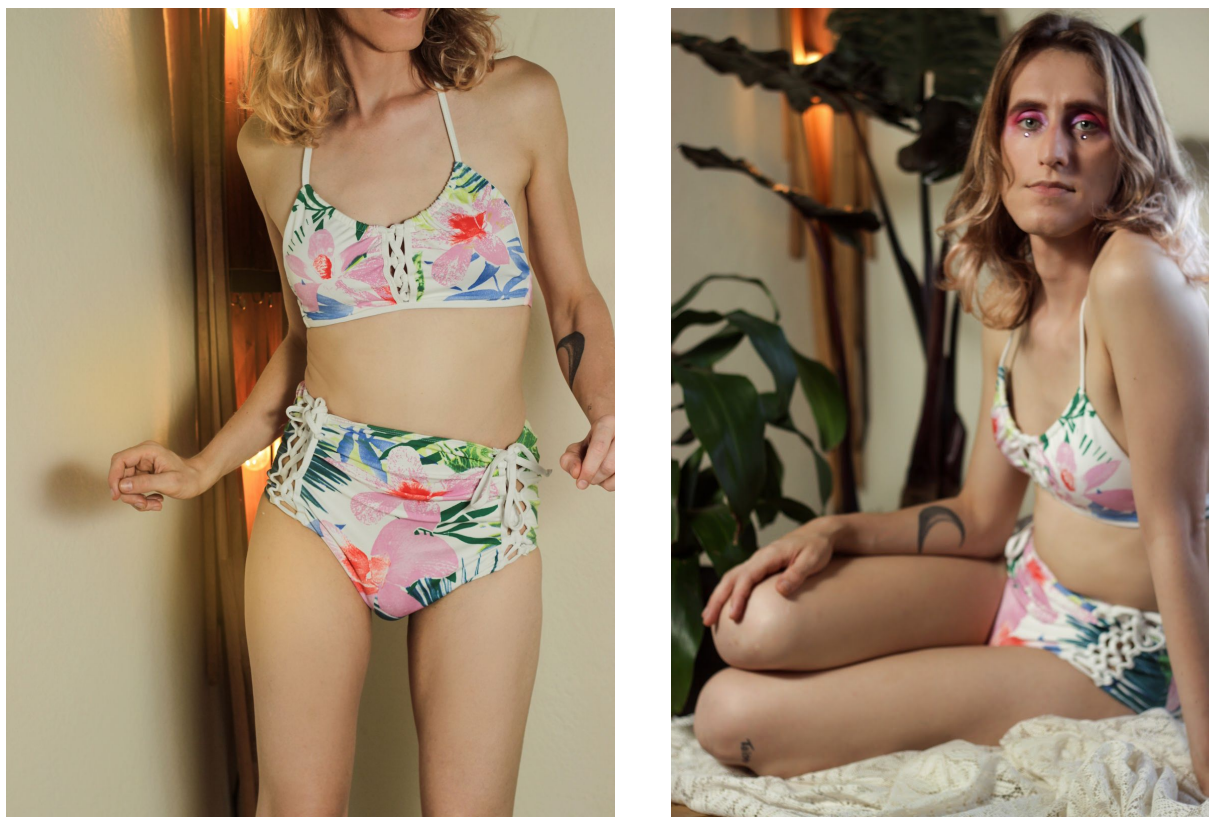

Fonte: Primária (2017).

\section{Considerações Finais}

A partir dos estudos gerados para o desenvolvimento deste artigo, percebe-se que a invisibilidade da população transsexual é uma das barreiras a serem enfrentadas no mundo e é um dos temas contemporâneos que precisam ser discutidos em todos os setores possíveis, para que haja realmente um entendimento sobre o assunto e para que as mesmas não sofram mais nenhum tipo de discriminação. Compreende-se, também, que a moda e o design possuem um papel relevante na sociedade quando se trata de inclusão.

Sabendo que o campo do design procura transformar as necessidades humanas em produtos ou serviços que visam a melhoria de sua qualidade de vida, e que, o papel do design extrapola a criação de produtos, passando a interferir sobre o comportamento dos usuários e sobre a forma "como os seres humanos relacionam-se através da influência mediadora dos produtos" (Buchanan, 2001). A partir dos estudos feitos para o desenvolvimento deste projeto, entendem-se a real importância de uma moda inclusiva, que repensa projetos e inova dentro do mercado, justamente porque consegue-se enxergar que existe um público de pessoas que precisam desse olhar atento para todos.

Apesar de o Brasil ter um registro histórico bastante relevante em produção de moda praia, sendo um setor de significância dentro da indústria e tendo papel fundamental na construção de uma moda nacional, é importante que o mercado invista não somente em originalidade em tecidos, estampas e modelos, mas também, entenda a importância de inovar idéias quanto às necessidades das pessoas e em todos os tipos de público. Fazendo isso, o país pode vir a se destacar novamente de forma mundial, com uma moda praia inclusiva e focada também para o público de mulheres transgênero. 


\section{Referências}

BUCHANAN, Richard. Design Research and the New Learning, 2011.

CIACCO, César Francisco. Inovar é um bem social. In: LEAL, Joice Joppert;

EBC. Eu, trans: quero te mostrar quem eu sou. Disponível em: 〈http://www.ebc.com.br/trans $>$ Acesso em: junho de 2018.

GOMES, Jaqueline de Jesus. Orientações sobre identidade de gênero: conceitos e termos. Guia técnico sobre pessoas transexuais, travestis e demais transgêneros, para formadores de opinião. p. 1-24, 2012.

IBGE: Instituto Brasileiro de geografia e estatística. Disponível em: https://www.ibge.gov.br/ Acesso em: 15 set. 2017

IIDA, Itiro. Ergonomia: projeto e produção, 2005.

KRUCKEN, Lia; TRUSEN, Christoph. A comunicação da sustentabilidade de produtos e serviços. Cadernos de Estudos avançados em design: Sustentabilidade, 2009 p. 59-68.

REIS, Neilton; PINHO, Raquel; Gêneros não binários: identidades, expressões e educação. p. 1-19, 2016.

WATKINSON, Matt. The ten principles behind great customer experience. UK: Publishing Financial Times, 2013. p. 240.

RODRIGUEZ, Ana María Mújica. Experiências de atenção à saúde e percepções das pessoas transgênero, transsexuais e travestis sobre serviços públicos de saúde em Florianópolis/SC, 2014.

Tereza Cabana. Moda trans para o mundo. Disponível em: <https://terezacabana.wordpress.com> Acesso em: junho de 2018. 